Check for updates

Cite this: RSC Adv., 2018, 8, 4867

\title{
Efficient carbazole-based small-molecule organic solar cells with an improved fill factor
}

\author{
Yongtao Liu, Yanna Sun, Miaomiao Li, Huanran Feng, Wang Ni, (DD Hongtao Zhang, * \\ Xiangjian Wan (D) and Yongsheng Chen (D) *
}

In this study, a new acceptor-donor-acceptor (A-D-A) small molecule, DI3TCz, with carbazole as the central unit and 1,3-indanedione as the end group, was designed and synthesized for application in organic solar cells. In contrast to the molecule DR3TCz with rhodanine as end groups, DI3TCz exhibited deep a LUMO energy level and a nearly unchanged HOMO energy level with a narrow optical band gap of $1.75 \mathrm{eV}$ and red shifted absorption. Compared with DR3TCz, the DI3TCz device showed a PCE of $6.46 \%$ with a remaining high $V_{\text {oc }}$ value of $0.97 \mathrm{~V}$, improved $J_{\text {sc }}$ of $10.40 \mathrm{~mA} \mathrm{~cm}^{-1}$ and a notable $\mathrm{FF}$ of 0.65 , which is the highest PCE value reported to data for carbazole-based small molecules OPVs.

Received 19th September 2017 Accepted 18th January 2018

DOI: 10.1039/c7ra10387e

rsc.li/rsc-advances acceptor (A-D-A) small molecules is mainly determined by the central donor unit, and the lowest unoccupied molecular orbital (LUMO) mainly depends on the terminal acceptor group. Recently, our group has reported a series of small-molecule donor materials with carbazole as the central building block. ${ }^{7}$ The devices based on those carbazole-derived small-molecule donor materials exhibit high $V_{\text {oc }}$ owing to the deep HOMO levels of the central carbazole unit. However, the $J_{\mathrm{sc}}$ and FF are not desirable, which is related to the narrow absorption of those molecules in the visible region and unfavourable active layers morphologies. Thus, there is much improved room of the device performance for above carbazole-based small molecules through careful molecules design and device optimizations.

In this study, we report a new small molecule DI3TCz with carbazole unit as the central building block and 1,3-indanedione as the end group. The molecule DI3TCz has the same molecular backbone as one of our previously reported small molecule DR3TCz (Scheme 1). The 1,3-indanedione unit has stronger electron withdrawing ability compared with rhodanine Felated to the open-circuit voltage $\left(V_{o c}\right)$, short-cir current density $\left(J_{\mathrm{sc}}\right)$, and fill factor $(\mathrm{FF})$. To achieve outstanding PCE, these parameters should be simultaneously optimized. ${ }^{5}$ Generally, SM-OPVs exhibit high $V_{\mathrm{oc}}$, low $J_{\mathrm{sc}}$ and FF in contrast to their polymer counterpart. Therefore, how to improve $J_{\mathrm{sc}}$ and $\mathrm{FF}$ without sacrificing the $V_{\mathrm{oc}}$ is an effective strategy for the PCE improvement of SM-OPVs. ${ }^{6}$

Recent studies have shown that the highest occupied molecular orbital (HOMO) energy level of acceptor-donor-

State Key Laboratory and Institute of Elemento-Organic Chemistry, The Centre of Nanoscale Science and Technology, Key Laboratory of Functional Polymer Materials, Collaborative Innovation Center of Chemical Science and Engineering (Tianjin), College of Chemistry, Nankai University, Tianjin, 300071, China. E-mail: htzhang@ nankai.edu.cn; yschen99@nankai.edu.cn

$\dagger$ Electronic supplementary information (ESI) available. See DOI: 10.1039/c7ra10387e

\begin{abstract}
unit. ${ }^{8}$ Thus, red shifted absorption of DI3TCz in contrast to
\end{abstract}

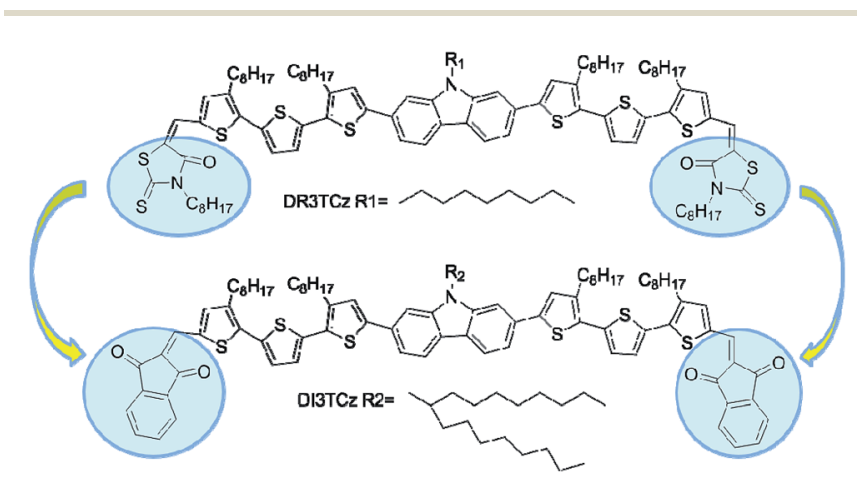

Scheme 1 Chemical structures of DR3TCz and DI3TCz. 
DR3TCz is expected after introducing the 1,3-indanedione end group. Meanwhile, the much planar structure of the 1,3-indanedione units may facilitate with phase separation in the active layer. On the other hand, in order to improve the solubility of DI3TCz, a large branched alkyl side chain, heptadecan-9-yl, was introduced on the $\mathrm{N}$ atom of the carbazole central unit of DI3TCz. As expected, OPV devices based on DI3TCz exhibit an much improved $J_{\mathrm{sc}}$ and FF compared with those of DR3TCz based devices ascribed to the better light absorption and favorable morphology of the active layer. A decent PCE with value of $6.46 \%$ was achieved. To our knowledge, it is the highest PCE value reported to date for carbazole-based small molecules OPVs.

\section{Experimental section}

\section{Materials and synthesis}

All reactions and manipulations were carried out under argon using standard Schlenk techniques. Scheme S1† shows the detailed procedures to synthesize DI3TCz. Compound 1,9-(heptadecan-9-yl)-2,7-bis(4,4,5,5-tetramethyl-1,3,2-dioxaborolan-2-yl)$9 H$-carbazole, was commercially obtained and used without

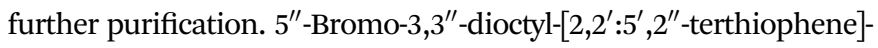
5-carbaldehyde and $5^{\prime \prime}, 5^{\prime \prime}$-(9-(heptadecan-9-yl)-9H-carbazole-2,7diyl)bis(3,3'-dioctyl-[2,2' $: 5^{\prime}, 2^{\prime \prime}$-terthiophene]-5-carbaldehyde) were synthesized according to literature. ${ }^{7 b}$

\section{Synthetic procedures}

DCHO3TCz (140 mg, $0.10 \mathrm{mmol}$ ) was dissolved in a solution of dry $\mathrm{CHCl}_{3}(50 \mathrm{~mL}) .1,3$-Indanedione $(146 \mathrm{mg}, 1.00 \mathrm{mmol})$ and three drops of triethylamine were added, and the resulting solution was stirred for $24 \mathrm{~h}$ under argon at room temperature. After solvent removal, the crude product was dissolved in $8 \mathrm{~mL}$ chloroform. To this solution, $\mathrm{CH}_{3} \mathrm{OH}(30 \mathrm{~mL})$ was added to precipitate out the product. The above dissolve and precipitate procedure was repeated several times to completely remove the unreacted 1,3-indanedione. Then, the product was separated by silica-gel chromatography using a mixture of dichloromethane and petroleum ether $(1: 1)$ as the eluent to afford DI3TCz as a black solid (120 mg, 72\% yield). ${ }^{1} \mathrm{H}$ NMR (400 $\mathrm{MHz}, \mathrm{CDCl}_{3}$ ): ס 8.01-8.06 (m, 2H), 7.93-7.97 (m, 4H), $7.87(\mathrm{~s}, 2 \mathrm{H}), 7.81(\mathrm{~s}, 2 \mathrm{H})$, 7.74-7.76 (m, 5H), $7.59(\mathrm{~s}, 1 \mathrm{H}), 7.49(\mathrm{~s}, 2 \mathrm{H}), 7.41-7.42(\mathrm{~b}, 2 \mathrm{H})$, 7.21-7.26 (b, 4H), 4.63-4.67 (m, 5H), $2.87(\mathrm{~s}, 8 \mathrm{H}), 2.36-2.40(\mathrm{~m}$, $2 \mathrm{H}), 1.99-2.03(\mathrm{~m}, 2 \mathrm{H}), 1.70-1.80(\mathrm{~m}, 8 \mathrm{H}), 1.44-1.47(\mathrm{~m}, 10 \mathrm{H})$, 1.30-1.35 (m, 40H), 1.16-1.20 (m, 14H), 0.87-0.89 (m, 12H), 0.78-0.81 (m, 6H). ${ }^{13} \mathrm{C} \mathrm{NMR}\left(100 \mathrm{MHz}, \mathrm{CDCl}_{3}\right): \delta 190.42,189.74$, 145.43 , 145.40, 144.13, 144.10, 142.05, 141.48, 140.73, 140.52, 139.16, 135.67, 134.94, 134.72, 128.17, 126.32, 126.08, 123.73, $122.93,122.76,120.78,120.55,117.30,108.57,105.84,56.62$, 33.89 , 31.96, 31.92, 31.80, 30.66, 30.19, 29.49, 29.38, 26.87, 22.73, 22.63, 14.16. MS (MALDI-TOF): calculated for $\mathrm{C}_{105} \mathrm{H}_{127} \mathrm{NO}_{4} \mathrm{~S}_{6}[\mathrm{M}]^{+}, 1659.53$; found 1660.27.

\section{Characterization}

The ${ }^{1} \mathrm{H}$ and ${ }^{13} \mathrm{C}$ NMR spectra were recorded on a Bruker AV-400 spectrometer. Matrix-assisted laser desorption/ionization time- of-flight mass spectrometry (MALDI-TOF MS) was carried out on a Bruker Autoflex III instrument. Cyclic voltammetry (CV) measurements were carried out on an LK98B II microcomputerbased electrochemical analyzer in dichloromethane solutions at room temperature using a conventional three-electrode configuration, with a glassy carbon electrode, a saturated calomel electrode, and a Pt wire as the working, reference, and counter electrodes. Dichloromethane was distilled from calcium hydride under dry argon immediately before use. Tetrabutylammonium phosphorus hexafluoride $\left(\mathrm{Bu}_{4} \mathrm{NPF}_{6}, 0.1 \mathrm{M}\right)$ in dichloromethane was used as the supporting electrolyte; the molecules were dissolved in the above dichloromethane solution before the measurement, and the scan rate was $100 \mathrm{mV} \mathrm{s}^{-1}$. UV-vis spectra were recorded on a JASCO V-570 spectrophotometer. Thermogravimetric analysis (TGA) was carried out on a NETZSCH STA 409PC instrument under a purified nitrogen gas flow at a heating rate of $10{ }^{\circ} \mathrm{C} \mathrm{min}^{-1}$. Atomic force microscopy (AFM) measurements were carried out using a Bruker MultiMode 8 instrument in the "tapping" mode. Transmission electron microscopy (TEM) images were recorded on a Philips Technical G2 F20 instrument at $200 \mathrm{kV}$.

The space-charge-limited current (SCLC) mobility was measured using the diode configuration of ITO/PEDOT:PSS/ donor: $\mathrm{PC}_{71} \mathrm{BM} / \mathrm{Au}$ for hole mobility and ITO/Al/donor: $\mathrm{PC}_{71} \mathrm{BM} /$ $\mathrm{Al}$ for electron mobility and fitting the results to a space-chargelimited form, where SCLC is described by

$$
J=\frac{9 \varepsilon_{0} \varepsilon_{\mathrm{r}} \mu_{0} V^{2}}{8 L^{3}}
$$

where $J$ is the current density, $L$ is the film thickness of the active layer, $\mu_{0}$ is the mobility, $\varepsilon_{\mathrm{r}}$ is the relative dielectric constant of the transport medium, $\varepsilon_{0}$ is the free-space permittivity $\left(8.85 \times 10^{-12} \mathrm{~F} \mathrm{~m}^{-1}\right)$, and $V\left(=V_{\text {appl }}-V_{\mathrm{bi}}\right)$ is the internal voltage in the device, where $V_{\text {appl }}$ and $V_{\mathrm{bi}}$ are the applied voltage to the device and the built-in voltage related to the relative work function difference of the electrodes, respectively.

The current density-voltage $(J-V)$ characteristics of photovoltaic devices were recorded on a Keithley 2400 sourcemeasure unit. The photocurrent was measured under a simulated illumination of $100 \mathrm{~mW} \mathrm{~cm}^{-2}$ (AM 1.5G irradiation) using a xenon-lamp-based solar simulator (SAN-EI XES-70S1) in an argon-filled glovebox. Simulator irradiance was characterized using a calibrated spectrometer, and the illumination intensity was set using a certified silicon diode. The external quantum efficiency values (EQEs) of the encapsulated devices were recorded using a halogen tungsten lamp, monochromator, optical chopper, and lock-in amplifier under air, and the photon flux was determined using a calibrated silicon photodiode.

\section{Results and discussion}

\section{Synthesis and thermal property}

Scheme 1 shows the chemical structure of DI3TCz, which was prepared by the Knoevenagel condensation of $\mathrm{DCHO} \mathrm{TCz}$ with 1,3-indanedione in the presence of triethylamine. Purification using conventional silica-gel chromatography, followed by recrystallization from chloroform and hexane, afforded the final 
product. The structure was verified by NMR and MALDI-TOFMS. The molecule DI3TCz is rather soluble in common organic solvents and exhibits good thermal stability up to $340{ }^{\circ} \mathrm{C}$ under $\mathrm{N}_{2}$ (Fig. $\mathrm{S} 1 \dagger$ ).

Fig. 1 shows the optical absorption of DI3TCz in solution (chloroform) and solid state (thin film). The detailed absorption data were summarized in Table 1 . The absorption data of DR3TCz were also given in Fig. 1 and Table 1 for comparison. As shown in Fig. 1 and Table 1, DI3TCz exhibits redshifted absorption in solution and solid state in contrast to that of DR3TCz. The shoulder peak in the film state, indicative of the effective $\pi-\pi$ packing between molecule backbones; this effective packing is beneficial for charge transport. ${ }^{9}$ Additionally, DI3TCz exhibits a considerably bathochromic shift from solution $(539 \mathrm{~nm})$ to solid state $(575 \mathrm{~nm})$ with a wide range. This result might be related to its reduced $\pi-\pi$ stacking distances between backbones and improved order after introduction of the 1,3-indanedione end group. ${ }^{10}$ The optical band gap of DI3TCz is $1.75 \mathrm{eV}$, which is much smaller than that of DR3TCz with value of $1.88 \mathrm{eV}$. The electrochemical properties of DI3TCz was investigated by cyclic voltammetry (CV). Ferrocene/ ferrocenium of the $\left(\mathrm{Fc} / \mathrm{Fc}^{+}\right)$redox couple $(4.8 \mathrm{eV}$ below the vacuum level) was used as the internal calibration. The HOMO and LUMO energy levels are -5.09 and $-3.46 \mathrm{eV}$, respectively. As shown in Table 1, DI3TCz has nearly same HOMO to that of DR3TCz because of the same carbazole central unit. While DI3TCz shows deeper LUMO values than that of DR3TCz ascribed to the stronger electron withdrawing ability of 1,3indanedione.

\section{Photovoltaic performance}

$\mathrm{BHJ}$ solar cells were fabricated using DI3TCz as electron donor and $\mathrm{PC}_{71} \mathrm{BM}$ as electron acceptor with a device structure glass/ ITO/PEDOT:PSS/donor:PC ${ }_{71} \mathrm{BM} / \mathrm{PrC}_{60} \mathrm{MA} / \mathrm{Al}$ and tested under the illumination of $\mathrm{AM} 1.5 \mathrm{G}, 100 \mathrm{~mW} \mathrm{~cm}{ }^{-2} \cdot \mathrm{PrC}_{60} \mathrm{MA}$ is a fullerene derivative for electron transport layer developed by Jen's group (Fig. S8†). The active layer was spin-coated from its

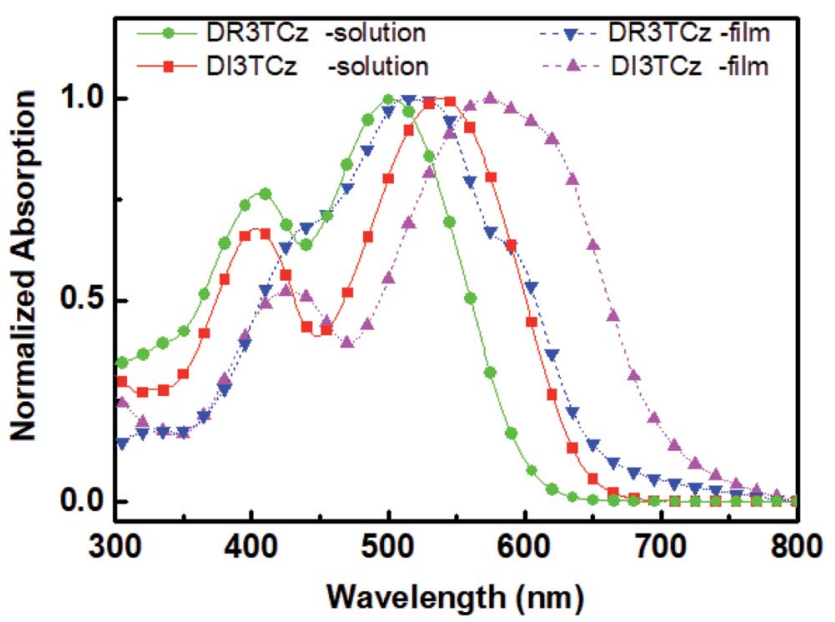

Fig. 1 UV-vis absorption spectra of DI3TCz and DR3TCz in chloroform solution and on the solid state.
Table 1 Optical and electrochemical data of DI3TCz

\begin{tabular}{llllll}
\hline Molecule & $\lambda_{\max }^{\text {sol }} / \mathrm{nm}$ & $\lambda_{\max }^{\text {film }} / \mathrm{nm}$ & $E_{\mathrm{g}}^{\mathrm{opt}} / \mathrm{eV}$ & $\mathrm{HOMO} / \mathrm{eV}$ & LUMO/eV \\
\hline DI3TCz & 539 & 575 & 1.75 & -5.09 & -3.46 \\
DR3TCz & 502 & 516 & 1.88 & -5.08 & -3.28
\end{tabular}

chloroform solution. The optimized blend ratio for DI3TCz was $1: 0.8$ (DI3TCz:PC $\left.{ }_{71} \mathrm{BM}\right)$ by weight. Fig. 2a shows the optimized $J-V$ curves of DI3TCz: $\mathrm{PC}_{71} \mathrm{BM}$ devices. The corresponding photovoltaic parameters are summarized in Table 2. For comparison, the best $J-V$ curve and photovoltaic parameters are given in Fig. 2a and Table 2. The DI3TCz-based device without post-treatment exhibits only a PCE of $3.07 \%$, with a $J_{\text {sc }}$ of 7.96 $\mathrm{mA} \mathrm{cm}{ }^{-1}$ and $\mathrm{FF}$ of 0.39 . The device performance significantly improves after solvent vapour annealing (SVA) with chloroform due to the significant enhancement of $J_{\mathrm{sc}}$ and FF. The optimal device exhibits a $V_{\mathrm{oc}}$ of $0.97 \mathrm{~V}$, a $J_{\mathrm{sc}}$ of $10.40 \mathrm{~mA} \mathrm{~cm}^{-1}$, and an $\mathrm{FF}$ of 0.65 , resulting in a PCE of $6.46 \%$. To our knowledge, this is the highest PCE value for carbazole-based small molecule OPVs to date. As shown in Table 2, the $V_{\mathrm{oc}}$ of DR3TCz:PC ${ }_{71} \mathrm{BM}$ device is nearly same as that of DR3TCz: $\mathrm{PC}_{71} \mathrm{BM}$ device, which is consistent with their similar HOMO levels. The $J_{\mathrm{sc}}$ of DI3TCz based device is much higher than that of DR3TCz ascribed to the broad and red shifted absorption of DI3TCz. Note, DI3TCz based device gives a notable FF of 0.65 , which is mainly attributed to the balanced mobility discussed below. Fig. $2 \mathrm{~b}$
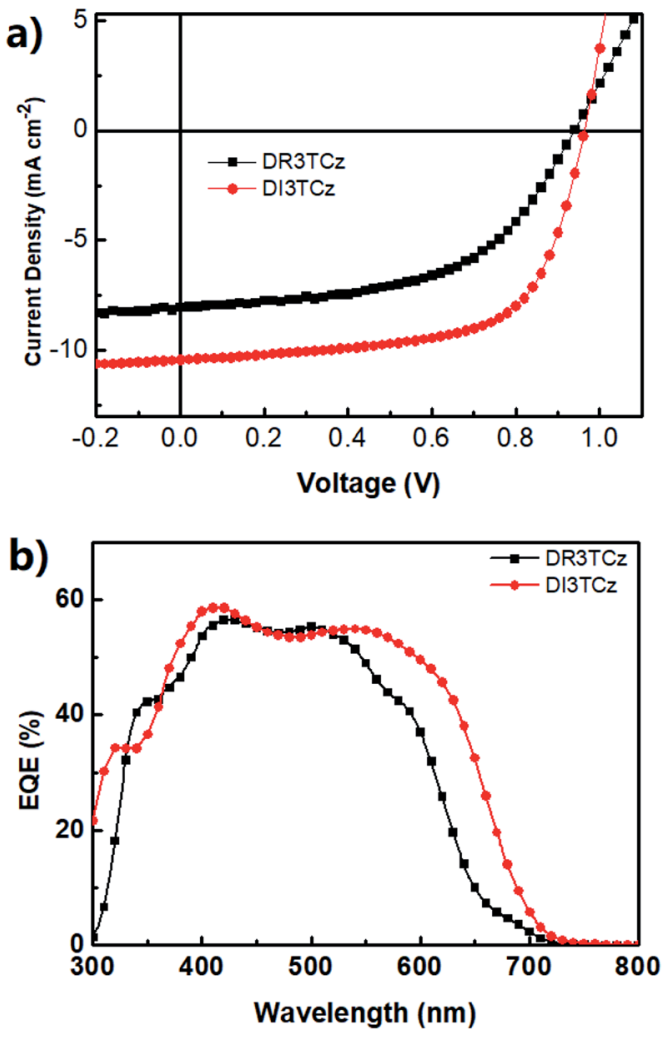

Fig. 2 (a) Typical $J-V$ curves of optimal devices based on DR3TCz:PC ${ }_{71} B M$ and DI3TCz:PC ${ }_{71} B M$. (b) EQE spectra of devices based on DR3TCZ:PC ${ }_{71} B M$ and DI3TCZ:PC ${ }_{71} B M$. 
Table 2 Photovoltaic parameters DI3TCz:PC ${ }_{71} \mathrm{BM}$ and DR3TCZ:PC ${ }_{71}$ BM based devices

\begin{tabular}{lccll}
\hline Devices & $V_{\mathrm{oc}} / \mathrm{V}$ & $J_{\mathrm{sc}} /\left(\mathrm{mA} \mathrm{cm}{ }^{-2}\right)$ & $\mathrm{FF}$ & $\mathrm{PCE}_{\max }\left(\mathrm{PCE}_{\mathrm{ave}}\right)^{a} / \%$ \\
\hline DI3TCz & 1.00 & 7.96 & 0.39 & $3.07(2.94)^{b}$ \\
& 0.97 & 10.40 & 0.65 & $6.46(6.14)^{c}$ \\
DR3TCz & 0.94 & 8.02 & 0.54 & $4.08(3.94)^{d}$
\end{tabular}

${ }^{a}$ Average values from 30 devices. ${ }^{b}$ As cast. ${ }^{c}$ SVA. ${ }^{d}$ Data from ref. $7 \mathrm{~b}$.

shows the EQE spectra of the optimal devices of DI3TCz. Compared with DR3TCz, DI3TCz based devices exhibits a broad photocurrent response from 300 to $700 \mathrm{~nm}$, which is consistent with the absorption spectra of the blend films and higher $J_{\mathrm{sc}}$ than that of DR3TCz based devices.

To understand the effect of SVA on photovoltaic performance of the DI3TCz-based devices, the relationship between the photocurrent $\left(J_{\mathrm{ph}}\right)$ and effective voltage $\left(V_{\text {eff }}\right)$ is obtained from the $J-V$ data and shown in Fig. 3. $J_{\mathrm{ph}}\left(J_{\mathrm{ph}}=J_{\mathrm{L}}-J_{\mathrm{D}}\right)$ is dependent on $V_{\text {eff }}\left(V_{\text {eff }}=V_{0}-V_{\mathrm{a}}\right)$, where $J_{\mathrm{L}}$ and $J_{\mathrm{D}}$ are the current densities under illumination and in the dark, respectively; $V_{\mathrm{a}}$ is the applied voltage; and the $V_{0}$ is the voltage at which $J_{\mathrm{ph}}=0 .{ }^{11} \mathrm{As}$ shown in Fig. 3, with increasing $V_{\text {eff }}$, the saturation photocurrent $\left(J_{\text {sat }}\right)$ for the DI3TCz-based devices after SVA treatment is attained earlier. And it value is greater than that of the as cast device. This result indicated that the DI3TCz-based device exhibited more efficient charge dissociation and collection after SVA treatment.

\section{Morphology, molecular ordering, and mobility}

Fig. $4 \mathrm{a}$ and $\mathrm{b}$ shows the atomic force microscopy (AFM) images of the active layer morphology. The blend film without posttreatment exhibits a root-mean-square (rms) surface roughness of $0.58 \mathrm{~nm}$ (Fig. 4a). After SVA, the rms roughness of the blend films slightly increases to $0.69 \mathrm{~nm}$ (Fig. $4 \mathrm{~b}$ ). Additionally, as shown in TEM images (Fig. $4 \mathrm{c}$ and d), after SVA treatment, the blend film based on DI3TCz:PC ${ }_{71} \mathrm{BM}$ exhibits clear phase separation with interpenetrating networks of donor and acceptor phases. That morphology is beneficial for the dissociation of

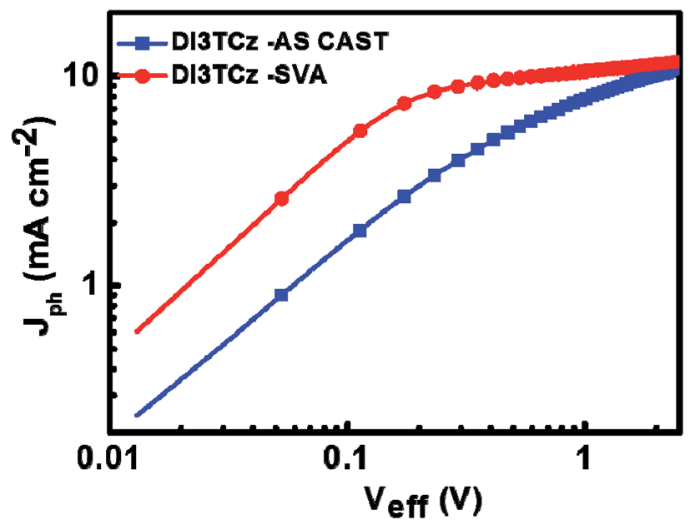

Fig. 3 Photocurrent density versus effective voltage $\left(J_{p h}-V_{\text {eff }}\right)$ for devices based on DI3TCZ:PC 71 BM.

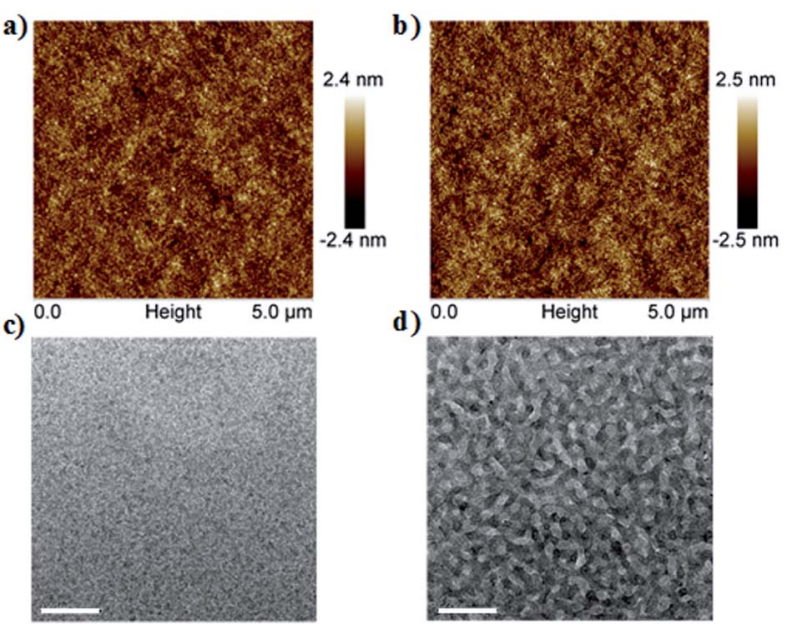

Fig. 4 ( $a$ and $b)$ Tapping-mode AFM-phase images of the active layers of DI3TCZ:PC ${ }_{71} B M$. (c and d) TEM images of DI3TCZ:PC ${ }_{71} B M$ blend films. ( $a$ and $c$ ) As-cast and ( $b$ and d) with SVA post-treatment.

excitons and charge transport, which is attributed to improvement of device FF and $J_{\mathrm{sc}}{ }^{12}$ The mobilities of the blend films were measured by the SCLC method. The hole and electron mobilities of DI3TCz:PC ${ }_{71} \mathrm{BM}$-based devices without post-treatment are $2.17 \times 10^{-5} \mathrm{~cm}^{2} \mathrm{~V}^{-1} \mathrm{~s}^{-1}$ and $2.35 \times 10^{-5} \mathrm{~cm}^{2} \mathrm{~V}^{-1} \mathrm{~s}^{-1}$, respectively. These values improved to $6.11 \times 10^{-5} \mathrm{~cm}^{2} \mathrm{~V}^{-1} \mathrm{~s}^{-1}$ and $4.30 \times 10^{-5} \mathrm{~cm}^{2} \mathrm{~V}^{-1} \mathrm{~s}^{-1}$, respectively, after SVA treatment. The improvement in hole and electron mobilities is consistent with the interpenetrating donor and acceptor networks morphology and attributed to the good FF of the devices.

\section{Conclusions}

In summary, we have designed and synthesized small molecule donor DI3TCz with 1,3-indanedione as the end group. In contrast to its rhodanine analogy DR3TCz, DI3TCz showed red shifted absorptions and nearly unchanged HOMO level. Compared with that of DR3TCz, the DI3TCz device showed a high $V_{\mathrm{oc}}$ value of $0.97 \mathrm{~V}$ and improved $J_{\mathrm{sc}}$ of $10.40 \mathrm{~mA} \mathrm{~cm}{ }^{-1}$. Additionally, a notably FF of 0.65 was achieved due to the interpenetrating donor and acceptor network morphology and balanced hole and electron mobilities. The PCE (6.46\%) achieved for optimized DI3TCz:PC71BM device is the highest PCE reported to data for carbazole-based small molecules OPVs. The enhancement in photovoltaic performance is attributed to the tuning of the absorptions and energy levels via the use of the acceptor indandione unit.

\section{Conflicts of interest}

There are no conflicts to declare.

\section{Acknowledgements}

The authors gratefully acknowledge the financial support from MoST (2014CB643502) and NSFC (91433101). 


\section{Notes and references}

1 (a) H. J. Zhang, Q. Zhang, M. M. Li, B. Kan, W. Ni, Y. C. Wang, X. Yang, C. X. Du, X. J. Wan and Y. S. Chen, J. Mater. Chem. C, 2015, 3, 12403-12409; (b) C. Yi, X. W. Hu, H. C. Liu, R. D. Hu, C. H. Hsu, J. Zheng and X. Gong, J. Mater. Chem. C, 2015, 3, 26-32; (c) K. Sun, Z. Y. Xiao, S. R. Lu, W. Zajaczkowski, W. Pisula, E. Hanssen, J. M. White, R. M. Williamson, J. Subbiah, J. Y. Ouyang, A. B. Holmes, W. W. H. Wong and D. J. Jones, Nat. Commun., 2015, 6, 6013; (d) Y. Z. Lin, Y. F. Li and X. W. Zhan, Chem. Soc. Rev., 2012, 41, 42454272; (e) Y. J. Cheng, S. H. Yang and C. S. Hsu, Chem. Rev., 2009, 109, 5868-5923; (f) W. Q. Chen, X. Yang, G. K. Long, X. J. Wan, Y. S. Chen and Q. C. Zhang, J. Mater. Chem. C, 2015, 3, 4698-4705; (g) L. M. Chen, Z. R. Hong, G. Li and Y. Yang, Adv. Mater., 2009, 21, 1434-1449.

2 (a) S. Q. Zhang, L. Ye, W. C. Zhao, B. Yang, Q. Wang and J. H. Hou, Sci. China: Chem., 2015, 58, 248-256; (b) Q. Zhang, B. Kan, F. Liu, G. K. Long, X. J. Wan, X. Q. Chen, Y. Zuo, W. Ni, H. J. Zhang, M. M. Li, Z. C. Hu, F. Huang, Y. Cao, Z. Q. Liang, M. T. Zhang, T. P. Russell and Y. S. Chen, Nat. Photonics, 2015, 9, 35-41; (c) J. B. You, L. T. Dou, K. Yoshimura, T. Kato, K. Ohya, T. Moriarty, K. Emery, C. C. Chen, J. Gao, G. Li and Y. Yang, Nat. Commun., 2013, 4, 1446; (d) L. Ye, S. Q. Zhang, L. J. Huo, M. J. Zhang and J. H. Hou, Acc. Chem. Res., 2014, 47, 15951603; (e) Y. H. Liu, J. B. Zhao, Z. K. Li, C. Mu, W. Ma, H. W. Hu, K. Jiang, H. R. Lin, H. Ade and H. Yan, Nat. Commun., 2014, 5, 13094; (f) C. Liu, C. Yi, K. Wang, Y. L. Yang, R. S. Bhatta, M. Tsige, S. Y. Xiao and X. Gong, ACS Appl. Mater. Interfaces, 2015, 7, 4928-4935; $(g)$ S. H. Liao, H. J. Jhuo, Y. S. Cheng and S. A. Chen, Adv. Mater., 2013, 25, 4766-4771; (h) B. Kan, Q. Zhang, M. M. Li, X. J. Wan, W. Ni, G. K. Long, Y. C. Wang, X. Yang, H. R. Feng and Y. S. Chen, J. Am. Chem. Soc., 2014, 136, 15529-15532; (i) F. Huang, Sci. China: Chem., 2015, 58, 190; (j) X. W. Hu, C. Yi, M. Wang, C. H. Hsu, S. J. Liu, K. Zhang, C. M. Zhong, F. Huang, X. Gong and Y. Cao, Adv. Energy Mater., 2014, 4, 1400378; (k) Z. C. He, C. M. Zhong, S. J. Su, M. Xu, H. B. Wu and Y. Cao, Nat. Photonics, 2012, 6, 591-595; (l) J. D. Chen, C. H. Cui, Y. Q. Li, L. Zhou, Q. D. Ou, C. Li, Y. F. Li and J. X. Tang, Adv. Mater., 2015, 27, 1035-1041.

3 (a) H. X. Zhou, L. Q. Yang, A. C. Stuart, S. C. Price, S. B. Liu and W. You, Angew. Chem., Int. Ed., 2011, 50, 2995-2998; (b) Y. M. Sun, G. C. Welch, W. L. Leong, C. J. Takacs, G. C. Bazan and A. J. Heeger, Nat. Mater., 2012, 11, 44-48; (c) A. Mishra and P. Bauerle, Angew. Chem., Int. Ed., 2012, 51, 2020-2067; (d) A. K. K. Kyaw, D. H. Wang, D. Wynands, J. Zhang, T. Q. Nguyen, G. C. Bazan and A. J. Heeger, Nano
Lett., 2013, 13, 3796-3801; (e) G. R. He, X. J. Wan, Z. Li, Q. Zhang, G. K. Long, Y. S. Liu, Y. H. Hou, M. T. Zhang and Y. S. Chen, J. Mater. Chem. C, 2014, 2, 1337-1345.

4 B. Kan, M. M. Li, Q. Zhang, F. Liu, X. J. Wan, Y. C. Wang, W. Ni, G. K. Long, X. Yang, H. R. Feng, Y. Zuo, M. T. Zhang, F. Huang, Y. Cao, T. P. Russell and Y. S. Chen, J. Am. Chem. Soc., 2015, 137, 3886-3893.

5 X. G. Guo, N. J. Zhou, S. J. Lou, J. Smith, D. B. Tice, J. W. Hennek, R. P. Ortiz, J. T. L. Navarrete, S. Y. Li, J. Strzalka, L. X. Chen, R. P. H. Chang, A. Facchetti and T. J. Marks, Nat. Photon, 2013, 7, 825-833.

6 (a) T. S. van der Poll, J. A. Love, T. Q. Nguyen and G. C. Bazan, Adv. Mater., 2012, 24, 3646-3649; (b) S. X. Sun, Y. Huo, M. M. Li, X. W. Hu, H. J. Zhang, Y. W. Zhang, Y. D. Zhang, X. L. Chen, Z. F. Shi, X. Gong, Y. S. Chen and H. L. Zhang, ACS Appl. Mater. Interfaces, 2015, 7, 19914-19922; (c) W. Ni, M. M. Li, X. J. Wan, H. R. Feng, B. Kan, Y. Zuo and Y. S. Chen, RSC Adv., 2014, 4, 31977-31980; (d) Y. S. Liu, C. C. Chen, Z. R. Hong, J. Gao, Y. Yang, H. P. Zhou, L. T. Dou, G. Li and Y. Yang, Sci. Rep., 2013, 3, 11547; (e) Q. D. Li, F. Liu, X. W. Hu, W. Z. Xu, L. P. Wang, X. H. Zhu, X. Gong and Y. Cao, IEEE Photonics J., 2015, 5, 1118-1124; (f) V. Gupta, A. K. K. Kyaw, D. H. Wang, S. Chand, G. C. Bazan and A. J. Heeger, Sci. Rep., 2013, 3, 1965.

7 (a) W. Ni, M. M. Li, B. Kan, Y. Zuo, Q. Zhang, G. K. Long, H. R. Feng, X. J. Wan and Y. S. Chen, Org. Electron., 2014, 15, 2285-2294; (b) H. R. Feng, M. M. Li, W. Ni, F. Liu, X. J. Wan, B. Kan, Y. C. Wang, Y. M. Zhang, Q. Zhang, Y. Zuo, X. Yang and Y. S. Chen, J. Mater. Chem. A, 2015, 3, 16679-16687.

8 G. K. Long, X. J. Wan, B. Kan, Y. S. Liu, G. R. He, Z. Li, Y. W. Zhang, Y. Zhang, Q. Zhang, M. T. Zhang and Y. S. Chen, Adv. Energy Mater., 2013, 3, 639-646.

9 (a) Y. Ruiz-Morales, J. Phys. Chem. A, 2002, 106, 11283-11308; (b) A. Guerrero, S. Loser, G. Garcia-Belmonte, C. J. Bruns, J. Smith, H. Miyauchi, S. I. Stupp, J. Bisquert and T. J. Marks, Phys. Chem. Chem. Phys., 2013, 15, 1645616462; (c) J. E. Anthony, Chem. Rev., 2006, 106, 5028-5048.

10 (a) C. Uhrich, R. Schueppel, A. Petrich, M. Pfeiffer, K. Leo, E. Brier, P. Kilickiran and P. Baeuerle, Adv. Funct. Mater., 2007, 17, 2991-2999; (b) M. Turbiez, P. Frere, M. Allain, C. Videlot, J. Ackermann and J. Roncali, Chem.-Eur. J., 2005, 11, 3742-3752.

11 (a) L. Y. Lu, Z. Q. Luo, T. Xu and L. P. Yu, Nano Lett., 2013, 13, 59-64; (b) P. W. M. Blom, V. D. Mihailetchi, L. J. A. Koster and D. E. Markov, Adv. Mater., 2007, 19, 1551-1566.

12 T. L. Nguyen, H. Choi, S. J. Ko, M. A. Uddin, B. Walker, S. Yum, J. E. Jeong, M. H. Yun, T. J. Shin, S. Hwang, J. Y. Kim and H. Y. Woo, Energy Environ. Sci., 2014, 7, 3040-3051. 